\title{
Decision Making in Selection Interviews
}

\author{
Adrian Banks, Julie Gore, Rebecca Smith \\ University of Surrey \\ a.banks@surrey.ac.uk,j.gore@surrey.ac.uk
}

\begin{abstract}
Motivation - To investigate how rapidly and accurately selection decisions are made in job interviews. Research approach - An experimental approach was used. Experienced HR professionals viewed videos of job interviews. The video was frozen at several points and a decision made. Research limitations/Implications - This research implies that HR professionals can accurately distinguish higher performing candidates after ten seconds and do not change this decision during the remaining interview. A wider range of interviews could be used in future to identify the cues used in the decision. Originality/Value - Whilst it is commonly reported that selection decisions are made rapidly, this research demonstrates that those decisions are not necessarily biased but can be accurate too. Also, the use of an experimental design is valuable as it removes the reliance on retrospective reports of decision processes. Take away message - Decisions made in selection interviews can be rapid and also accurate.
\end{abstract}

Keywords

Selection decisions, organizational decision making.

\section{INTRODUCTION}

The aim of this study is to develop NDM research in organisations, strengthening the links between NDM and organizational decision making (e.g. Gore, Banks, Millward, \& Kyriakidou, 2006). Specifically, we will investigate how selection decisions are made based on job interviews. These decisions are common and have a significant impact on the organization. They are also somewhat mysterious. Whilst research clearly indicates the benefits of longer structured interviews (e.g. Schmidt \& Hunter, 1998) it remains common for interviewers to describe situations in which they knew that 'the interviewees face fitted'. The idea that interviews can be determined by 'snap decisions' is an old one (e.g. Springbett,1958) but one that chimes well with NDM theories of decision making based on pattern recognition such as Recognition-Primed Decision Making. Therefore this study was designed to discover (a) how quickly decisions based on job interviews are really made and (b) how accurate these decisions are.

A second aim of the research is to explore the utility of experimental methods in NDM research. There have been several suggestions that NDM would benefit from a balance of different research methods (e.g. Lipshitz, Klein, Orasnu, \& Salas, 2001). Lab and field research is not a simple dichotomy as both can vary in their generalisability to different situations. It is certainly possible, for example, to study experts in more controlled settings without completely eliminating the key elements of their expertise. In this study we used experienced Human Resource professionals to make selection decisions based on interviews. They each viewed the same videos of the interviews to ensure comparability across their decisions. This also enabled the video to be frozen at various points and judgements made, meaning that the decision could be charted as it developed rather than retrospectively.

\section{METHOD}

Four interviews were conducted with candidates for a general sales role in an organisation. These four varied in their sales experience. The interviews were videoed and viewed by twenty experienced Human Resource professionals. During viewing, the videos were paused after an initial ten second period before the candidate spoke and after each of the three interview questions. At each of these times the participants were asked to rate on a five point scale how competent the individual was for a sales role and how confident they were in their decision. Participants were not given prior information about the candidates' experience and it was not directly referred to in the interview. 


\section{RESULTS}

The four candidates interviewed were divided into two 'experienced' candidates and two 'inexperienced' candidates. The ratings for these two groups were then compared to establish if the participants could accurately identify the less experienced candidates. The ratings were compared across the four time periods to discover how rapidly these decisions were made.

Table 1:Ratings of competence over the interview

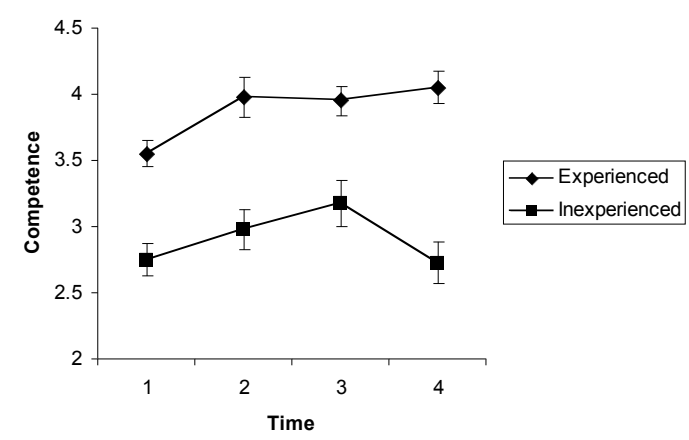

Table 2: Ratings of confidence in decision

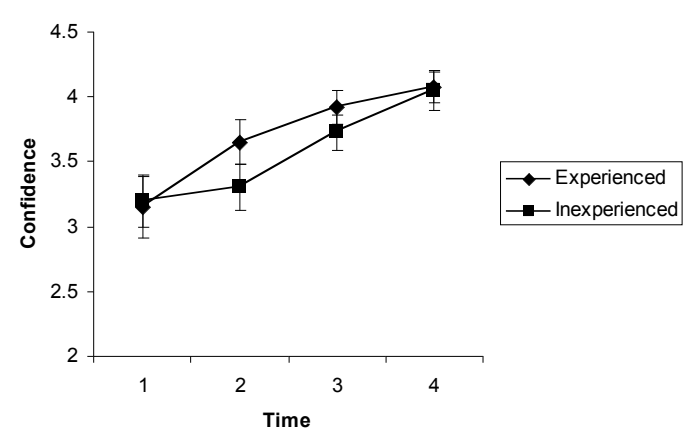

Participants rated the experienced candidates more highly than the inexperienced ones $(\mathrm{F}(3,57)=4.88)$, $\mathrm{p}<0.05$, even at the first time point $(\mathrm{t}(19)=5.45, \mathrm{p}<0.0001)$. Post hoc tests with a Bonferroni adjustment were used to investigate how these ratings changed over time. Ratings of experienced candidates increased from time 1 to time $2(t(19)=-2.67$, $\mathrm{p}<0.017)$ but remained the same between time 2 and $3(\mathrm{t}(19)=0.21, \mathrm{p}>0.017)$ and time 3 and $4(\mathrm{t}(19)=-1.29, \mathrm{p}>0.017)$. Ratings of inexperienced candidates did not change between time 1 and $2(\mathrm{t}(19)=-1.31, \mathrm{p}>0.17)$ or time 2 and 3 ( $\mathrm{t}(19)=$ -2.18, $\mathrm{p}=0.017)$ before decreasing between times 3 and $4(\mathrm{t}(19)=5.11, \mathrm{p}<0.017)$.

Participants confidence in their judgments did not differ between experienced and inexperienced candidates $(\mathrm{F}(3,57)=$ $3.20, \mathrm{p}>0.05)$ but they did increase steadily over time $(\mathrm{F}(3,57)=27.23, \mathrm{p}<0.0001)$.

\section{DISCUSSION}

This study provides support for the idea that selection decisions based on job interviews are both rapid and accurate. HR professionals rated experienced candidates higher than inexperienced candidates based on a short interview. In fact, they were able to distinguish between them after the first ten seconds of viewing the video, before they had spoken. Ratings of experienced candidates increased after the first question and then remained at the same level for the rest of the interview. This pattern suggests an initial judgment was made based on the appearance of the candidate but it is their response to the first question which determined the decision. The pattern of ratings of inexperienced candidates is less clear. In contrast, the ratings of confidence in the decision linearly increased throughout the interview. This suggests that whilst the decision may be made rapidly, information from the remainder of the interview is used to support that decision further. Overall, decisions are made quickly, heavily influenced by the first answer the candidate provides. These decisions are accurate too; experienced candidates are rated more highly than inexperienced candidates.

\section{REFERENCES}

Gore, J., Banks, A., Millward, L.J., \& Kyriakidou, O. (2006). Naturalistic Decision Making and organisations: Reviewing pragmatic science. Organization Studies, 27, 925-942.

Lipshitz, R., Klein, G., Orasanu, J., and Salas, E. (2001). Focus article: Taking stock of naturalistic decision making. Journal of Behavioral Decision Making, 14, 331-352.

Schmidt, F. L. \& Hunter, J. E. (1998). The validity and utility of selection methods in personnel psychology: Practical and theoretical implications of 85 years of research findings. Psychological Bulletin, 124, 262-274.

Springbett, B.M. (1958). Factors affecting the final decision in the employment interview. Canadian Journal of Psychology, 12, 13-22. 